\title{
Some Investigations of Educational and Occupational Scenerio Of Scheduled Castes Population Of Assam: A Case study of Kaibartta (Fisherman) Community
}

\author{
Biman Lahkar ${ }^{1}$, Prof. Lakshahira Datta ${ }^{2}$ \\ ${ }^{I}$ Research Scholar Department of Geography, Gauhati University, Guwahati \\ ${ }^{2}$ Professor and ex. HOD Dept of Geography, Gauhati University, Guwahati, Assam
}

\begin{abstract}
The system of cast based society is perhaps the most troubled topic of Indian social fabric. Nowhere in the world can one find such a disgraceful division of life. This paper is a sincere effort to study and explore the present condition of the suppressed class people in the state of Assam. The kaibarttas are one of the most prominent subgroup of scheduled caste people living in the state, whose main occupation is fishing. They are also the largest community of SC population living here. So by studying the educational and occupational characteristic of the Kaibarttas, attempt is being made to understand the status of the zipped community who were deprived of all basic amenities of a civil society in earlier times.
\end{abstract}

Key words: Kaibartta, cast, fishing, S.C., community

\section{The Problem}

In our country the system of caste based society has probably aroused the major portion of controversy in Indian life. According to the sixth schedule of the constitution of India scheduled castes populace of India is regarded as weaker fragment of Indian class based society. The Indian constitution arranged some privilege and safeguard for the interest of this segment of people. The Government has also made large scale stipulation for social, cultural, educational and economic uplift of the people of these castes groups. It may be noted that, the president of India by public notification under Article 341(I) of the Constitution of India listed and declared them socio economically backward.

The most comprehensive explanation of demographic and socio-economic indicator of scheduled castes people in India details not only the high concentration of poverty and substandard living conditions, but also the insecurity of tenure and marginalization form the formal sector, including basic services, education etc.

The scheduled castes population, a constituent group of the region's populace is a native and aboriginal group of people who, in the wake of Aryan colonization of India came into the close contact with the sociocultural routine of the Aryans and subsequently tailored to the Hindu lifestyle. In the antique times the privileged class form by the Aryans acquired societal power in the society and considered the smaller groups of native population as subordinates to them. These groups eventually came to be recognized as the Sudras conforming to the lowest stratum in the cast hierarchy of the Hindus. The present scheduled castes belong to such a Sudra community in India, most of them are considered as 'untouchables' in different part of the country. 'Two fundamental and primary strata within the Hindu society are the ritually higher castes and the untouchables, officially called the "Scheduled castes". The Vast majority of the members of the scheduled castes are engaged in certain unclean or menial hereditary occupations which the higher caste people consider socially degrading. Consequently, they have remained at the bottom of the caste hierarchy and usually at a very low economic level'. (S.M. Bhardwaj and ME. Harvey.)

The inhabitants of present Kamrup district of Assam are constituted by diverse ethnic groups with varied socio-cultural attributes. Dating back from the antediluvian period diverse ethno-linguistic groups had entered the valley from unknown lands and established in its native. Presently according to the census of India there are as many as 16 scheduled castes faction in Assam, according to the scheduled castes and scheduled tribes modification order 1956 (1). It is observed that out of the sixteen castes, only seven are native to Assam. They are viz, Mali, Bania, Hira, Jalkeout, Jhalomalo, Kaibartta and Mahara. The two other castes Dholi Dugla and Patni are to a certain extent indigenous and partly immigrant in origin, especially the immigrants of them came from erstwhile East Bengal and Bihar. The seven other groups, who are entirely of immigrant origin, came especially from erstwhile East Bengal and Bihar during the pre-Independence period. These seven groups are Namasudra, Sutrdhar, Dhobi, Lalbegi, Bansphor, Mehtor and Munchi. According to 2001 Census, 85 per cent of the SCs are living in rural areas. Individual SC wise, there is wide variation with regard to their rural-urban distribution of population. A high of 27.9 per cent urban population has been recorded among Dhobi, followed by Brittial Bania with 23.3 per cent. On the contrary, Patni has recorded the lowest of 7.3 per cent urban 
population. Namasudra, Hira, Muchi, and Kaibartta are predominantly residing in rural areas having more than 85 per cent rural population.

An analysis of spatial distribution of scheduled castes population reveals that the Cachar district has the highest proportion of the scheduled castes population to the total population (14.41 percent) followed by Karimganj, Morigaon, Hilakandi, Bongaigaon and Nagaon, districts with 12.99 percent, 12.93 percent, 10.91 percent 10.25 percent,9.30percent respectively. The lowest proportion of scheduled castes population is found in N.C.Hills district claiming only 1.79 percent (2001). The total scheduled castes population of Kamrup district is 170541 people, which is 6.76 percent of the total population. The comparison of rural urban variation in the distribution of scheduled castes population in Assam shows that a rural area accounts for 84.25 percent of scheduled castes population, while only 15.75 percent are urban dwellers.

Studies revealed that the settlements of the indigenous scheduled castes are concentrated in the areas where there are ample opportunities for practicing their craft and occupations fruitfully. The rivers and the wetlands with ample fish, availability of soil suitable for pottery making and markets for such products produced by them determine the settlement pattern of scheduled caste population. The scheduled castes people are living in abject poverty and are also surviving in severe nutritional conditions. Among the scheduled castes, more than 50 percent of population lives below poverty line. Therefore it is necessary to make them aware to improve the quality of life. So an attempt has been made in this study to analyze the education, occupation and health condition of this weaker section of people in the society which will help the planners to formulate strategies for their development.

In the present study the main emphasis is given to the education and occupation of this weaker section of people in the society. It is because the illiteracy and low attainment level of education, discouraging employment pattern, low income level and poor health along with prevalence of social evils like drug addiction, criminal activities etc. are the most important area, improvement of which will change the life style from poor downtrodden people to a normal living.

The scenario is depressing in the case of the education sectors due to economic backwardness of the scheduled castes people the percentage of school dropout student is alarmingly high among them, education is essential for modernization of society. In the study area the literacy rate among the scheduled castes people is considerably low. This due to their economic backwardness on one hand and infrastructural backwardness in the areas they live on the other. Hence proper study is much needed in this field.

\section{Data base and Methodology}

Methodology in simpler words refers to research technique of a discipline. It may be mentioned that the philosophy of discipline changes with time; its research techniques also undergo a change so as to meet the requirement of the widened subject matter. Collection and analysis of data from various sources for evolving a conceptual framework suitable to the context of education and occupational structure of scheduled cast population is done through primary and secondary sources. Quantitative approach has been used in analysis of basic statistical data. Beyond that the study ceases to be statistical and also modern advanced techniques like Geographic Information System, GPS etc has been used for mapping and collection of relevant data. The study involves consideration of a variety of extra-economic and non-quantifiable variables that help us understand the social relations and processes. As regards the collection of empirical data the primary data will be collected through extended door to door interviews using questionnaires and schedules and secondary data from various sources supplemented by different journals books and research papers are used. Government publications like Statistical Hand book Assam (2008), Govt. of India census repot 2001; university publications mainly the Journal of NEIGS North Eastern Geographer, various Ph. D. theses related to the topic, international publications from internet source etc. immensely helped in supporting the data and information for the work.

\section{Need and Significance of the Study}

The worth of a research work in any academic field depends upon its benefit to the society. The study on education and occupation of Scheduled caste people is significant in a number of ways. It is reported that the total scheduled castes population of Kamrup district is 170541(2001) people, which is 6.76 percent of the total population, but the data in report gives no indication of the conditions in which they live. There is no data on how many of the Scheduled caste people have access to various services. Since projects are being proposed for the Scheduled caste people, there has to be some data and analysis presented for taking up these projects. The Programme to uplift the scheduled castes people being proposed for millions and millions of rupees needs to be elaborated to indicate which aspects will be covered and what will be the cost of providing the services

The absence of detailed or accurate data limits the ability of officials to detect accurate problems and thereby approximately allocate resources. Prompt identification of local socio-economic concerns is the first step in any intervention. There is a pressing need for a new analytic framework to understand the status of education in Scheduled caste people inhabited areas. 
Accurate educational and occupational statistics are difficult to obtain, and these statistics rarely report rural-urban differences. The inability to collect or analyze detailed data masks gross disparities within areas. Currently, most Scheduled caste people literacy data are based on census reports, data of directorates of concern dept. This underestimates the underlying conditions, as due to privacy norms census or government agencies are unable to generate data. Hence there is a pressing need for a new analytic framework to understand education and occupation among Scheduled caste population.

\section{Case study}

Kaibarttas are one of the most prominent groups among the scheduled caste communities inhabiting in Assam since long. According the census of India Kaibarttas are the largest scheduled caste communities of Assam having a total population of 294809 constitute $32.4 \%$ of the total Scheduled caste population of the state during 1971 census and become 581,559 constituting $31.8 \%$ of the total S.C. population during 2001. As the community is not residing in a compact area or a specific location it is a herculean task to get accurate data of the kaibarttas and frame a proper action plan for their upliftment. The kaibarttas are spread over 770 villages in Assam, they are predominant in rural areas and accounts for more than 85 percent of total kaibarttas. There are different suggestions from different scholars regarding the origin of the term kaibartta, but in well accepted general sense we use the term to indicate the fishing community among the Scheduled castes population of Assam. In this regard two other communities Nadials and the Doams are also part of the kaibarttas.

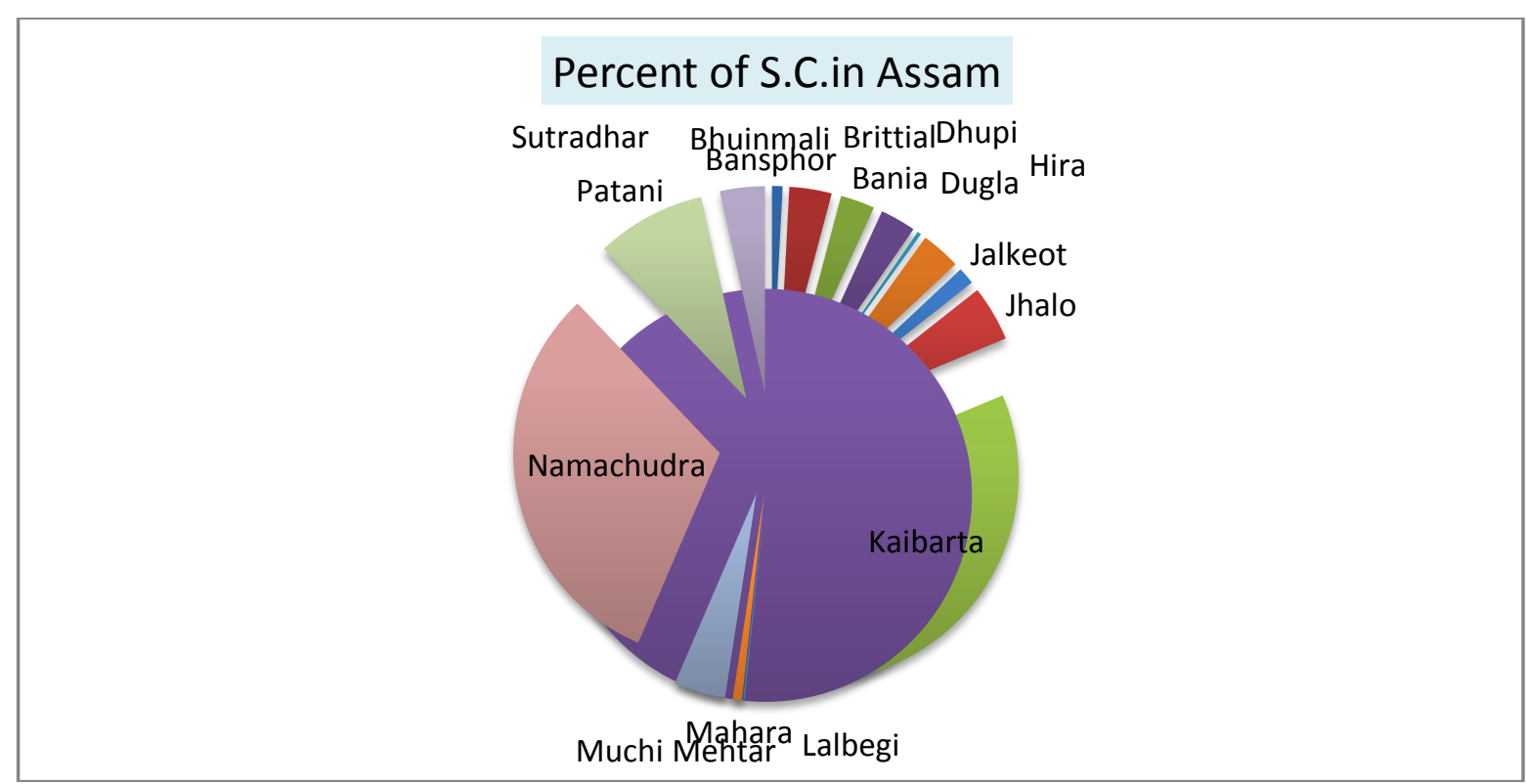

Figure: Proportion of SC population in Assam

Table-1: Scheduled Caste Population, 2001

\begin{tabular}{lll}
\hline \multicolumn{1}{c}{ Name of the Scheduled Caste } & \multicolumn{1}{c}{ Total population } & $\begin{array}{c}\text { Proportion to the total } \\
\text { SC population }\end{array}$ \\
& $1,825,949$ & 100 \\
\hline 1 Assam & & 0.8 \\
\hline 2 Bansphor & 14,760 & 3.2 \\
3 Bhuinmali & 57,974 & 2.6 \\
4 Brittial Bania & 47,974 & 2.7 \\
5 Dhupi & 49,929 & 0.3 \\
6 Dugla & 6,364 & 3.0 \\
7 Hira 55,106 3.0 & 55,106 & 1.3 \\
8 Jalkeot & 23,511 & 4.2 \\
9 Jhalo & 77,533 & 31.8 \\
10 Kaibartta 31.8 & 581,559 & 0 \\
11 Lalbegi & 552 & 0.1 \\
12 Mahara & 1,725 & 0.7 \\
13 Mehtar & 12,715 & 3.9 \\
14 Muchi & 70,954 & \\
\hline
\end{tabular}


Some Investigations Of Educational And Occupational Scenerio Of Scheduled Castes Population Of

\begin{tabular}{lll}
\hline 15 Namasudra & 555,621 & 30.4 \\
16 Patni & 151,992 & 8.3 \\
17 Sutradhar & 62,032 & 3.4 \\
\hline
\end{tabular}

Source: Census of India, 2001, Basic Statistical Abstract, Assam 2001

Literacy

The trend of literacy pattern among the Scheduled caste population in Assam is well above the literacy rate of schedule caste population of the nation as a whole and also above the literacy rate of Assam. The literacy rate of kaibartta community is $72.1 \%$ which is $66.8 \%$ among all scheduled caste communities of Assam and $54.7 \%$ for the nation. The literacy rate clearly indicates the fact that the kaibartta community is not lacking behind in education, but the gender gap among all the groups are very high. Especially among the kaibartta community, the literacy rate among the male are 80.5 it is only $63.3 \%$ among the female. Effective planning for the upliftment of the female population is much needed at this point of time. According to the 2001 Census, 64.6 per cent of the SC population in the age group 5-14 years has been attending schools or any other educational institutions. Brittial Bania have recorded the highest 78.1 per cent, closely followed by Dhupi (72 per cent), Hira (71.9 per cent), and Kaibartta (70 per cent). It is comparatively lower among Muchi (50.6 per cent), Jhalo (56.3 per cent), and Namasudra (59.4 per cent). The SCs having educational level graduation and above are only 2.5 per cent.

Jalkeot with 4.7 per cent and Brittial Bania with 4.3 per cent are well ahead of others. On the contrary Muchi have registered less than one per cent of their total literates having this level of education. It is also low among Jhalo (1.3 per cent), Sutradhar (1.7 per cent), Namasudra (1.8 per cent), and Patni (1.9 per cent).

Table3: Literacy Rate among Major SCs

\begin{tabular}{l|l|l|l|l|}
\cline { 3 - 5 } SI. No. & Name of the Scheduled caste group & \multicolumn{3}{l|}{ Literacy Rate ( 7 years and above) } \\
\cline { 3 - 5 } & & Total & Male & Female \\
\hline $\mathbf{1}$ & All S.C. & 66.8 & 75.7 & 57.1 \\
\hline $\mathbf{2}$ & Bhuinmali & 72.2 & 79.8 & 64.0 \\
\hline $\mathbf{3}$ & Brittial Bania & 81.0 & 88.6 & 73.0 \\
\hline $\mathbf{4}$ & Dhupi & 76.0 & 83.1 & 68.3 \\
\hline $\mathbf{5}$ & Hira & 72.5 & 82.7 & 61.8 \\
\hline $\mathbf{6}$ & Jalkeot & 69.3 & 78.9 & 58.8 \\
\hline $\mathbf{7}$ & Jhalo & 52.8 & 64.3 & 40.3 \\
\hline $\mathbf{8}$ & Kaibartta & 72.1 & 80.5 & 63.3 \\
\hline $\mathbf{9}$ & Muchi & 47.9 & 60.4 & 34.2 \\
\hline $\mathbf{1 0}$ & Namasudra & 60.2 & 70.1 & 49.4 \\
\hline $\mathbf{1 1}$ & Patni & 75.9 & 81.5 & 69.9 \\
\hline $\mathbf{1 2}$ & Sutradhar & 67.2 & 76.6 & 57.2 \\
\hline
\end{tabular}

Source: Office of the Registrar General, India 2001

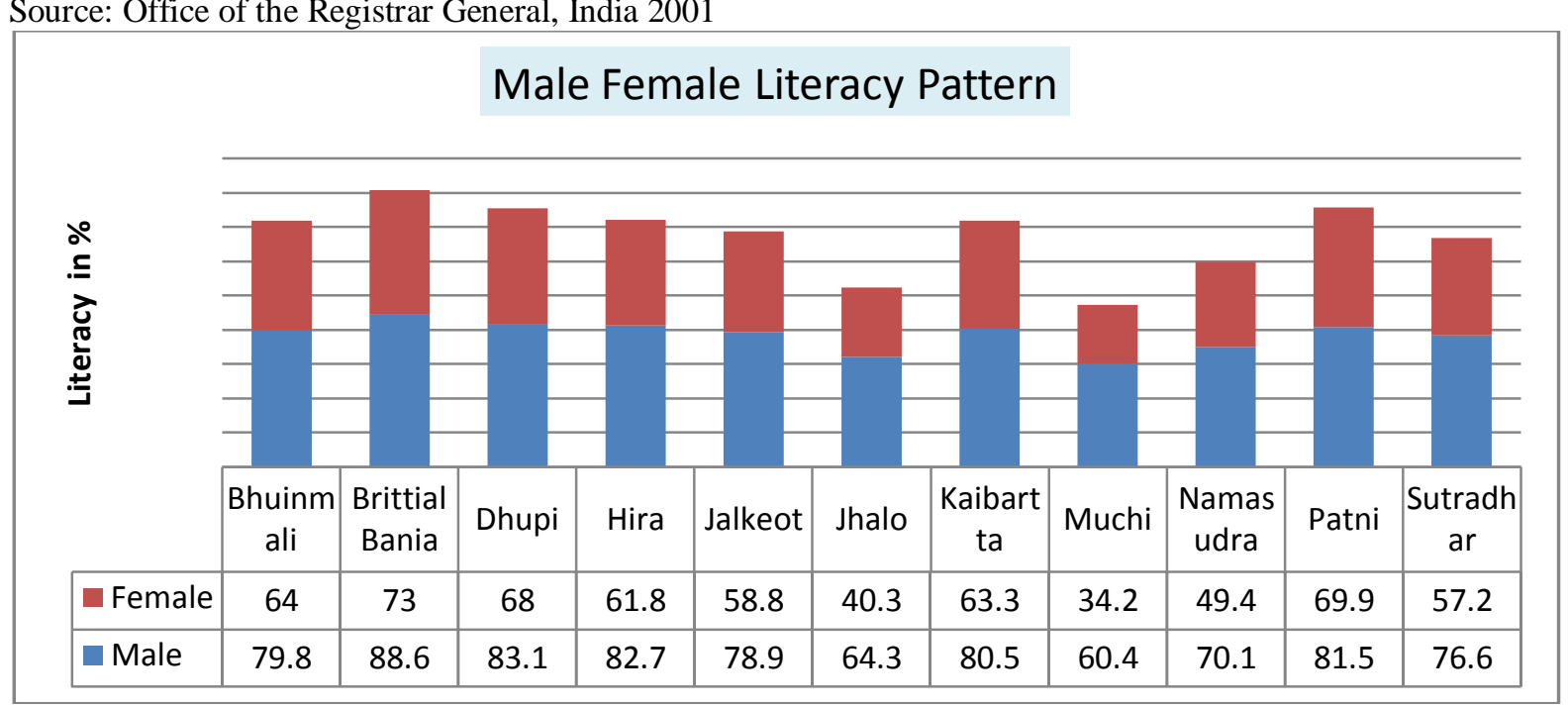

Figure: Male female literacy pattern in Assam 
Occupational Structure

The kaibartta community is well-known as the fishing community of Assam. As fishing is the means of their livelihood they possess the requisite expertise in this field. It is observed that due to many socio-economic factors they are shifting their traditional occupation and switching over to other occupations like agriculture, service, daily wage labour etc. The table below indicates the occupational structure of Kaibartta gaon of Kamrup rural district, Assam showing the changing occupational structure in the last ten years.

OCCUPATIONAL PATTERN AND CHANGES WITH TIME

\begin{tabular}{|lllllll|}
\hline $\begin{array}{l}\text { Occupation } \\
\text { Year }\end{array}$ & $\begin{array}{l}\text { No of families } \\
\text { surveyed }\end{array}$ & Fishing & Agriculture & Labour & Service & Others \\
\hline $\mathbf{2 0 0 1}$ & 48 & 36 & 5 & - & - & 7 \\
\hline $\mathbf{2 0 1 0}$ & 48 & 28 & 11 & 2 & 1 & 6 \\
\hline
\end{tabular}

Source: Primary data collected from field

The survey clearly reveals the fact that due to many reasons the kaibarttas has changed their traditional practice for earning bread. The primary set back is high dependence on mahaldars and unavailability of own fishing ground. Moreover high rate of uncertainty of weather and other conditions restricts the productivity.

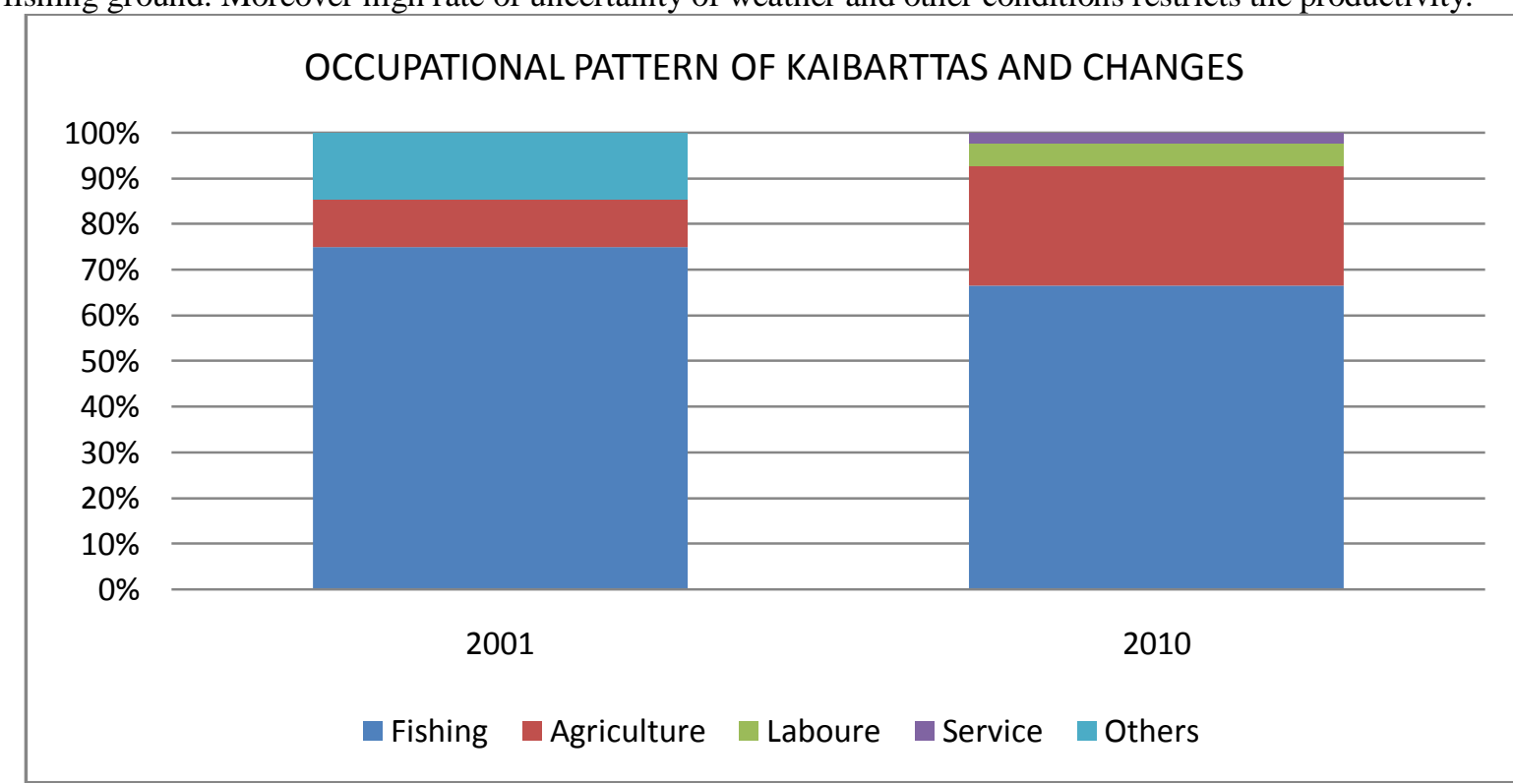

Figure: Occupational pattern of kaibarttas and its changes through time

Findings: The major findings of the study are

$>$ Kaibarttas are the largest group in Assam constituting around 31.8 percent

$>$ The rate of literacy among the kaibarttas is 72.1 percent and male literacy $(80.5 \%)$ is much higher than the female Literacy (63.3\%) showing a huge gender gap among them.

$>$ The kaibarttas are shifting their traditional occupation and switching over to other occupations like agriculture, service, daily wage labour etc. the main reason behind the change in profession are low level of income, high dependence on the mahaldars, unavailability of local fishing grounds etc.

\section{Conclusion}

The kaibarttas till recent time were the prominent fishing community of our state who are no longer practicing the tradition as their exclusive source of living. It is a very negative sign for the development of the fishing industry of Assam which is striving for its very existence. Presently Assam imports a heavy amount of fish from other part of India and allowing our capital floating outside, proper planning in this field will defiantly bring prosperity to both the community and the state as well.

\section{References}

[1]. Bhadra, K.R. (1990): Caste and Class in Assam. Social Inequality in India Profiles at Caste, Class and Social Mobility. Rawat Publication, Jaipur and New Delhi.

[2]. Chandana, R.C. (1989): Spatial Dimensions of Scheduled castes in India, Intellectual Publicity House, New Delhi.

[3]. Census of India (1991): Primary Census Abstract of scheduled caste and schedule tribe, Assam part II -B series- 4.

[4]. Directorate of Economics and Statistics: Statistical Hand Book, Assam. Govt. of Assam, Guwahati. (1980, 1994, 1996, 2009)

[5]. Datta, L. (1998): “A Glimpse of Population Growth In Undivided Nagaon District”. The Souvenir of North East India Geographical Society, Guwahati. 